\title{
Road to Somewhere: Understanding Factors Influencing Study Abroad Participation
}

\author{
Darren Walters \\ Drexel University \\ This paper was presented at the 2018 International Summit of the \\ Music \& Entertainment Industry Educators Association \\ March 22-24, 2018
}

\section{https://doi.org/10.25101/18.19}

\begin{abstract}
This study focuses on factors that influence study abroad participation within Drexel University's Music Industry Program. Music Industry Program students have historical low enrollment in study abroad; however, study abroad may increase global awareness and cultural competency, valuable assets for entering the globalized music industry. This study employs a program-wide survey and interviews with students who have and have not studied abroad to assess global awareness, cultural competency, and factors which influence the decision to study abroad. Findings yield the negative consequences of excluding global music industry information from curriculum and the financial, academic, and value considerations which affect choice. These results present the opportunity to address the significance of global music industry course material, curricular flexibility, and relevant study abroad courses needed to produce substantive growth within Drexel's Music Industry Program, while offering beneficial information to other music programs interested in expanding their study abroad programs.

Keywords: study abroad, global awareness, cultural competency, music industry education, student exchange, international programs, curriculum
\end{abstract}

\section{Introduction}

In an era where globalization is omnipresent and connectivity is a click away, society continues to attempt to understand what globalization means to the individual. Within higher education this manifests itself in the term global awareness. Governments and researchers often cite global awareness as a preventive measure to ensure that "diplomacy, foreign affairs, national security, or commerce and finance" are dealt with accordingly in the global economy (Commission on the Abraham Lincoln Study Abroad Fellowship Program 2005). In terms of how this corresponds with curricula, "engendering global citizenship identity leads students to endorse pro-social values (e.g., valuing diversity) and behaviors (e.g., environmental sustainability) and may aid in preparing students to function in the interconnected world" (Gibson and Reysen 2013).

In addition, the last decade has provided proof that study abroad, in any form, is an excellent method for attaining global awareness and skills. As Braskamp, Braskamp, and Merrill state, "Education abroad is a value-added experience. That is, student engagement in education abroad experiences enhance global learning and development" (2009). However, even with increased validation of study abroad and improved participation, the fact remains that, "Although the total number is at an all-time high, it is still the case that only about 10 percent of all U.S. undergraduate students... will study abroad by the time they graduate" (Institute of International Education 2016) which could lead to decreased global awareness, economic and national security, market stability, and educational aptitude.

This need for global awareness is particularly evident within the music industry, especially with the ongoing proliferation of digital music, global music companies, and the multitude of unexplored opportunities in countries that have yet to come "online" and experience music to its fullest. Music, like other businesses, is no longer restricted by terrestrial boundaries. This is evidenced in the vast global consumption of video and audio music streaming from companies such as YouTube, Spotify, and Apple Music and in 
countries as varied as "United States, Canada, Great Britain, France, Germany, Spain, Italy, Sweden, Australia, Japan, South Korea, Brazil, and Mexico [that] account for $84 \%$ of the global recorded music market [source: IFPI]" (Ipsos Connect 2016). However, the cultural nuances, laws, and practices of the consumers provide a complicated backdrop in which to navigate. Therefore, a depth of understanding is needed in order to untangle the web of how these territories work. Cultural immersion, study abroad, and knowledge of the global industry have proven to be a method to increase problem-solvers in other fields and music industry students would be prudent to follow their lead.

However, within Drexel University's Music Industry Program (MIP), there is scant participation in study abroad programs. According to Ahaji Schreffler, Associate Director of Drexel's Study Abroad Program, since 2008, Music Industry Program student participation in study abroad programs, whether offered as part of the Music Industry Program or other programs, has been just "41 MIP" (personal communication, March 13, 2017) students out of 1318, from data available since 2010 .

It is critical to understand what factors influence participation and what barriers, if any, exist in order to initiate change in study abroad participation among Music Industry Program students. The consequence for music industry students who opt not to study abroad is that they could lose the proven opportunity to, as Kitsantas notes, "enhance... cross-cultural skills and global understanding" (2004) which can have a catastrophic outcome not only upon their own careers, but the music industry, too, which requires innovative thinking and a global mindset to drive advancement and growth in the field.

Therefore, as the music industry enjoys continued worldwide expansion, there will be an increased need for creative individuals who possess global awareness with the ability to understand the global music environment. Evidence supports that programs such as study abroad, "that put our students in face-to-face contact with people of different cultures... seem to have the greatest likelihood of producing positive outcomes" (Anderson et al. 2008), as a proven method for increasing global awareness, so Music Industry Program students who fail to participate in these programs are therefore at risk of suffering from potential deficiency in the area.

Music Industry Program students who do not engage in study abroad may also be at a risk of reduced competency in the music industry, where an absence of global experience can be detrimental because without the knowledge, individuals may not have the "cross cultural skills and global understanding" (Kitsantas 2004) that is essential to working in today's globalized music business environment. In the music industry, a literal world of multi-faceted individu- als, these key experiences and attitudes are essential tools for success. The music industry is in constant transition, is comprised multinational companies, and requires individuals enabled with skills to deal with individuals, projects, and companies with unique perspectives and circumstances from around the globe.

However, despite the aforementioned, among Music Industry Program students, study abroad participation remains low, due to the fact that it is often not part of curriculum and also an additional source of cost for participants, among other reasons. Study abroad can vary in cost depending on length and location, and therefore one most often cited cause is financial, thus, "The cost of the program can be a major contributing factor to participation" (Smith and Mrozek 2016). A potential lack of corollary between curriculum and study abroad, exclusion of certain groups, such as freshmen, and lack of outreach, information, and understanding of possible benefits, such as the "satisfaction one can get from study abroad...from learning new things, meeting new people and gaining competence in another language" (Li, Olsen, and Frieze 2013) in addition to proselytizing that study abroad is not simply a vacation for wealthy students devoid of value, have also been known to impede participation. So, while "students are graduating into an increasingly complex and interrelated world where business, personal, and ethical decisions need to be made by informed and engaged practitioners" (Hatschek 2011) they are perhaps not recognizing that exposure to foreign ideas and cultures is critical to their careers which may disadvantage them in their career path. Thus, it is imperative that music industry students recognize that without a study abroad experience, they may be limiting their connection to the global music industry.

This study seeks to understand what benefits study abroad may contribute to Music Industry students so that these advantages can be expressed to all Music Industry Program students and faculty and utilized in curriculum and marketing of study abroad opportunities. Music Industry students are lacking the critical experience in the global sphere and it is important to explore what factors may impede participation. To that end, this study will attempt to answer the following:

1. What are Music Industry Program students' views in relation to global awareness?

2. What are Music Industry Program students' views in relation to cultural competency?

3. What factors influence students' decision to study abroad?

In order to best address the research questions, a mixed-methods approach will serve as the platform for this research. Both quantitative and qualitative methods are re- 
quired in order to uncover data and to validate the information exposed by each method used such as those employed in studies by Doyle et al. (2010) and Salyers et al. (2015).

\section{Literature Review}

In a global society, understanding and situating the individual's role in the world is imperative. Key to this is global awareness, which allows individuals to develop and understand the world through the context of a connected civilization in which all of humanity can gain from the understanding of one another. In Clarke's survey "of students' global awareness and personal involvement...to examine their international attitudes" (2004), Clarke found that global awareness is higher when a global curriculum environment exists and that significant gains can be made by exposure to cultures other than one's own. This is supported by Braskamp, Braskamp, and Merrill who concluded that study abroad is an effective means for enhancing the global learning of individuals and that participants "show the greatest gains in their self-assessment in the Cognitive domain, especially their knowledge of international affairs and cultural understanding" (2009). Their study also indicated the significant value that cultural immersion plays in the development of an individual by increasing how students view themselves in relation to others, become comfortable among other cultures, and develop proficiency in understanding the importance of cultures other than their own, resulting in an overall commitment to global citizenship and respect for individuals and cultures. The research of Wang et al. not only validates that exposure to other cultures through study abroad allows for the growth of students' global outlook due to "experience, reflection, and reconstruction" (2014), but does so regardless of length. However, this research also revealed that the most potent combination for increased global awareness is the dual offering of core classes that address global issues bolstered by short-term study abroad offerings.

In order to understand the importance of study abroad to global careers, Norris and Gillespie (2009), conducted a survey of 3,723 alumni of the Institute for the International Education of Students programs between 1950 and 1999 and found that recent alumni exhibited almost two times as much interest in working in another country, working for a multinational based in the United States was increased by three times, private sector work that included international elements was doubled, and participation in study abroad internships increased tenfold. In addition, alumni working in global careers were twice as likely to report that study abroad had an influence on initiating relationships that blossomed into industry contacts. Correlating research from Clarke III et al. (2009) confirms study abroad as enabling cultural competency, most notably "the abilities to under- stand different worldviews, adapt new cultural skills, and shift between cultural groups [that] could become important intercultural success factors" (Clarke III et al. 2009). Additionally, "creative problem solving is enhanced by studying a foreign culture" according to Cho and Morris (2015), which can help students synthesize relevant material and create culturally meaningful business scenarios. This in turn can lead to increased higher-level thinking, such as the ability to produce solutions to unconventional problems in a multitude of complex and varied cultural environments which is a desired talent in business, and certainly the music industry, where diversity is commonplace.

In the United State alone, "the number of U.S. students studying abroad for credit during the 2014-2015 academic year grew 2.9 percent" (NAFSA n.d.). With this growth has come greater scrutiny as to what factors may influence individual participation. As indicated in previous studies, Stroud found that gender was a key determinate factor, with 2.4 times more females than males intent on studying abroad (2010). Also, individuals who already had expressed interest in learning more about other places and cultures were more than two times as likely to study abroad. Of significant importance to this particular study, Stroud found a low intent to study abroad could be caused by "inflexible requirements within the major [that] impede certain majors from even considering study abroad" (2010). Drexel's Music Industry Program students may suffer from this attitude due to a constricted curriculum that offers little opportunity to make up classes lost to time studying abroad.

The cost of studying abroad can also be a massive issue. Salisbury et al. (2009) found a positive correlation between socioeconomic status and intent to study abroad, with students who are not financially solvent in or prior to attending college, unlikely to study abroad. Doyle (2010) found that although cost was a mitigating factor, unawareness or lack of knowledge of programs made decision-making more complicated for students. In addition, the study revealed that students were reluctant to study abroad due to the possibility of having to leave behind loved ones, potentially studying in another language, or facing obstacles to degree completion. On a positive note, students noted a variety of reasons to study abroad, including personal and career growth, academic interests, and interest in other cultures. While there is no guaranteed method for increasing the path towards participation in study abroad, as evidenced by the examination of the literature from Stroud (2010), Salisbury et al. (2009) and Doyle et al. (2010), there are ways to improve and provide excellent information on building research methods for attempting to understand the factors that influence Drexel University's Music Industry Program students' decision to study abroad. 


\section{Methodology}

This study utilized a mixed-method approach in a sequential format that combined the use of a student survey and student interviews. Information from the research of Stroud (2010), Doyle et al. (2010), Salisbury et al. (2009), Lorz et al. (2016), and Norris and Gillespie (2008), were critical resources in creating key survey and interview questions in order to ascertain new knowledge relevant to the study abroad community.

The study took place at Drexel University, a mid-sized private urban university located in Philadelphia, Pennsylvania with 15,499 undergraduates, where the Music Industry Program is comprised of two concentrations, Business and Recording Arts and Music Production (RAMP).

\section{Survey}

A quantitative, non-random closed-ended survey was administered to a purposely selected Music Industry Program undergraduate group of 217 students, including seniors who had recently graduated, in order to provide a comprehensive four-year cohort of students. The survey was sent via email to all Music Industry Program students using their Drexel email addresses. Each email contained a brief explanation of the purpose of the study and an informed consent form with an embedded link to the survey, all of which may be found in Appendix A. As an added enticement to complete the survey, participants were invited to enter to win a $\$ 25$ gift card upon successful completion of the survey.

The 33-question survey (see Appendix B) was divided into four sections: demographics, global awareness, cultural competency, and factors influencing study abroad participation. Rudimentary non-identifying demographics were used as the dependent variables for both portions of the survey and provided baseline background data and gathered utilizing multiple-choice questions. The variables of students' global awareness, cultural competency, and factors influential to impacting the student study abroad decision-making process were extracted by employing a combination of a five-point Likert scale, multiple choice, and yes/no questions that probed perceptions of general global awareness (how students situate themselves to other cultures), in relationship to the music industry curriculum, and what factors impact decision to study abroad.

\section{Interviews}

Interviews provided qualitative data from a purposeful sample of Music Industry Program students regarding their views in relation to global awareness and cultural competency and their decision to study abroad or not. All subjects are currently, or had been, business concentration students in the Music Industry Program and four had previously studied abroad while four had not. The group was comprised of four males and four females of which one student was a junior, two were seniors, and five were recent program graduates. Interviews were chosen as a secondary method of data collection because they allow subjects to express themselves more significantly. Interview requests were sent via email and contained a brief explanation of the purpose of the study and an informed consent form (see Appendix C).

The 22-question open-ended interview (see Appendix D) was administered on an individual basis and inquired about what interested the student in study abroad, how study abroad may have impacted the individual's level of global awareness and cultural competency, and whether the student perceived an increase in cultural sensitivity and intercultural communication skills.

In comparison, a 17-question open-ended interview (see Appendix E) was conducted with the students who had not studied abroad in order to compare and contrast responses from the cohort that did study abroad. The goal of these interviews was to compare these students' experiences to those of the study abroad students. Some questions were altered, or removed and replaced with new questions, in order to elicit feedback directly related to this group.

\section{Data Analysis and Results:}

\section{Survey Results}

Survey data was compiled into statistically relevant information and sorted to determine impact and influence of individual criteria. The survey garnered a response from 36 individuals, or $16.6 \%$ of the program, with females accounting for $61 \%$ of the respondents and males $39 \%$. $83 \%$, identified as White, with $11 \%$ identifying as Other, $2.78 \%$ as Hispanic or Latino and $2.78 \%$ as Asian or Pacific Islander. $64 \%$ of respondents were from the Business concentration and 36\% from the Recording Arts and Music Production concentration.

Global Awareness - Survey questions 8 through 17 were employed to analyze Music Industry Program students' views in relation to global awareness. For question 8 , Have you ever visited a foreign country?, $83.3 \%$ of students answered affirmatively. This result speaks favorably to a general basis for a better-than-average global awareness as individuals who have been abroad "showed changes in how they relate to persons unlike them and their commitment to becoming more global citizens" (Braskamp et al. 2009). Perhaps due to the high percentage of individuals surveyed who have had out-of-country experiences, questions 11 through 17 (see Table 1) include other highlights in global awareness, including favorable responses to questions 12, 13 , and 17 , positioning respondents' global awareness as above average.

As research by Clarke (2014) suggests, a supportive curricular environment may enhance global awareness in stu- 


\begin{tabular}{|c|c|c|c|c|c|c|c|}
\hline Questions & $\begin{array}{c}\text { Not at } \\
\text { all }\end{array}$ & $\begin{array}{c}\text { Small } \\
\text { degree }\end{array}$ & $\begin{array}{l}\text { Moderate } \\
\text { degree }\end{array}$ & $\begin{array}{l}\text { High } \\
\text { degree }\end{array}$ & $\begin{array}{l}\text { Very High } \\
\text { Degree }\end{array}$ & No & Yes \\
\hline $\begin{array}{l}\text { Q11. I believe that the world and its cultures are all } \\
\text { connected. }\end{array}$ & & & $16.67 \%$ & $58.33 \%$ & $25.00 \%$ & & \\
\hline Q12. I have listened to non-English language music. & & & & & & & $100 \%$ \\
\hline Q13. I have watched or read a non-U.S. news source. & & & & & & $16.67 \%$ & $83.33 \%$ \\
\hline $\begin{array}{l}\text { Q14. I become informed on controversial international } \\
\text { issues prior to developing a point of view. }\end{array}$ & & $11.11 \%$ & $44.44 \%$ & $38.89 \%$ & $5.26 \%$ & & \\
\hline $\begin{array}{l}\text { Q15. I consider current issues that affect individuals } \\
\text { living in developing countries. }\end{array}$ & & $25.00 \%$ & $38.89 \%$ & $25.00 \%$ & $11.11 \%$ & & \\
\hline $\begin{array}{l}\text { Q16. I am informed of issues that affect global securi- } \\
\text { ty, economics, human rights, and the environment. }\end{array}$ & & $19.44 \%$ & $55.56 \%$ & $16.67 \%$ & $8.33 \%$ & & \\
\hline $\begin{array}{l}\text { Q17. Equality and justice are human values that } \\
\text { should extend to all groups of individuals regardless of } \\
\text { race, religion, or lifestyle. }\end{array}$ & & & $2.78 \%$ & $11.11 \%$ & $86.11 \%$ & & \\
\hline
\end{tabular}

Table 1. Survey results from questions measuring Drexel Music Industry Program Student global awareness.

dents and eventually lead to interest in study abroad, so to understand how curriculum figured into global awareness and whether Drexel's Music Industry Program offered any correlation between classes offered and knowledge of the global market place, questions 9 and 10 specifically focused on curriculum. When asked question 9, Have you ever taken a course at Drexel University that involved the study of a foreign culture?, 57\% responded "yes" and 44\% "no". However, whether any of the classes students took that involved the study of a foreign culture had much impact should be given consideration given the replies to question 10, Drexel University's Music Industry Program classes have helped me to draw connections with the global music industry. The most popular option, garnering $43 \%$ of all responses, was "small degree". In fact, a total of $97 \%$ of respondents, all but one, answered "moderate degree" or lower (see Figure 1) illustrating that perhaps Drexel's Music Industry Program may not adequately address the role of the interna-

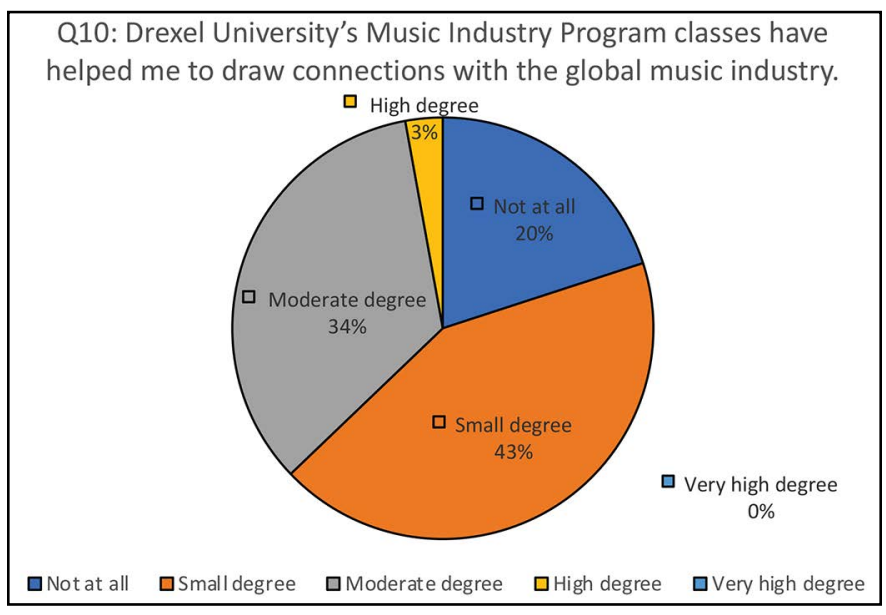

Figure 1. Connections between Drexel Music Industry Program curriculum and international music industry tional music industry in its curriculum. This, in turn, can lead to less global awareness, and also lower enrollment in study abroad programs due to a lack of information on the environment outside of the United States.

Cultural Competency - Survey questions 18-23 were used to examine the research question regarding the cultural competency of students. While all of the questions received better-than-average results, three out of five resulted in the highest percentage response with more than $50 \%$ of respondents choosing, "very high degree" (questions 19, 20, 21; see Table 2). The survey population reacted strongly to these three questions which addressed cultural, religious, racial, sexual and ideological differences and student comfort with, and exposure to, those whose lifestyle may be different than their own. These survey findings illustrate a moderate to very high degree of cultural competency for respondents - evidence that Drexel Music Industry Program students are situated well-within the spectrum of reasonably culturally competent individuals within a diverse and culturally complex world.

Factors Influencing Study Abroad Participation - The remaining set of survey questions, 24 through 33 (see Table 3 ), sought to illicit specific responses in order to understand why a student would or would not study abroad and what, if any, reason would factor into that choice. The results from this question set revealed far more interest in study abroad than had been previously understood to exist. Evidence of this can be seen in the answer to question 24, Are you interested in studying abroad?, which saw a response of $47.22 \%$ for "very high degree". However, the next few survey results illustrate that high levels of student interest may not necessarily translate into increased study abroad participation. For instance, for question 25, Are you aware of the current Music Industry Program study abroad options to 


\begin{tabular}{|c|c|c|c|c|c|}
\hline Question & $\begin{array}{l}\text { Not at } \\
\text { all }\end{array}$ & $\begin{array}{c}\text { Small } \\
\text { degree }\end{array}$ & $\begin{array}{l}\text { Moderate } \\
\text { degree }\end{array}$ & $\begin{array}{l}\text { High } \\
\text { degree }\end{array}$ & $\begin{array}{l}\text { Very High } \\
\text { Degree }\end{array}$ \\
\hline Q18. I seek out diverse individuals and situations. & & & $50 \%$ & $38.89 \%$ & $11.11 \%$ \\
\hline Q19. I am comfortable around individuals from other cultures. & & & $13.89 \%$ & $33.33 \%$ & $52.78 \%$ \\
\hline $\begin{array}{l}\text { Q20. Part of a college education should include exposure to individuals, } \\
\text { cultures, races, ideas, and sexualities that are different than my own. }\end{array}$ & & $2.78 \%$ & $8.33 \%$ & $19.44 \%$ & $69.44 \%$ \\
\hline $\begin{array}{l}\text { Q21. I respect the right of individuals to participate in cultures, religions, and } \\
\text { family structures different from my own. }\end{array}$ & & & & $22.22 \%$ & $77.78 \%$ \\
\hline Q22. I am open-minded and resist stereotypes about those unlike myself. & & & $13.89 \%$ & $52.78 \%$ & $33.83 \%$ \\
\hline Q23. My beliefs and value systems are more important than others. & & $19.44 \%$ & $55.56 \%$ & $16.67 \%$ & $8.33 \%$ \\
\hline
\end{tabular}

Table 2. Survey results from questions measuring Drexel Music Industry Program Student cultural competency.

Brazil and Australia?, 36.11\% answered "to a very great extent", indicating an awareness of current opportunities within the program. Yet question 26, Does program cost influence your decision to study abroad?, perhaps illuminates why Music Industry Program students historically do not study abroad with a combined total of $75 \%$ of students responding, "to a great extent" and above. Arguably related is question 30, Do work and/or co-op commitments influence your decision to study abroad?, in which $36.11 \%$ of students responded, "to a great extent" demonstrating that a loss of income or increased curricular strain may also be an important factor as cited in Salisbury et al. (2009) who discusses the impact of the strain that financial factors can have on students' decisions. However, the largest single response in this survey section came from question 33, Is it important to have real life experiences that connect with what you have learned in the Music Industry Program?, of which $55.56 \%$ of all respondents resoundingly answered, "to a very great extent", as it appears that students would prefer to be able to make connections between curriculum and what they may learn while studying abroad in order to intensify their experiences.

\section{Interview Results}

After interviews had been completed and transcribed, they were reviewed and coded according to trends and categories that appeared to create a comprehensive understanding of the data. As open coding occurred and categories were created, information was charted for further analysis and correlated with emerging themes. More weight was given to particular interview questions that directly correlated with the research questions and matched with survey data to substantiate findings and validate the results.

\begin{tabular}{|c|c|c|c|c|c|}
\hline Question & Not at all & $\begin{array}{l}\text { Small } \\
\text { degree }\end{array}$ & $\begin{array}{l}\text { Moderate } \\
\text { degree }\end{array}$ & $\begin{array}{c}\text { High } \\
\text { degree }\end{array}$ & $\begin{array}{l}\text { Very High } \\
\text { Degree }\end{array}$ \\
\hline Q24. Are you interested in studying abroad? & $2.78 \%$ & $19.44 \%$ & $13.89 \%$ & $16.67 \%$ & $47.22 \%$ \\
\hline $\begin{array}{l}\text { Q25. Are you aware of the current Music Industry Program study abroad } \\
\text { options to Brazil and Australia? }\end{array}$ & $2.78 \%$ & $13.89 \%$ & $30.56 \%$ & $16.67 \%$ & $36.11 \%$ \\
\hline Q26. Does program cost influence your decision to study abroad? & & $2.78 \%$ & $22.22 \%$ & $38.89 \%$ & $36.11 \%$ \\
\hline Q27. Is study abroad location important to you? & $5.56 \%$ & $16.67 \%$ & $30.56 \%$ & $33.33 \%$ & $13.89 \%$ \\
\hline $\begin{array}{l}\text { Q28. Is study abroad in a non-English language location important, even if } \\
\text { instruction will be in English? }\end{array}$ & $11.11 \%$ & $13.89 \%$ & $50.00 \%$ & $16.67 \%$ & $8.33 \%$ \\
\hline $\begin{array}{l}\text { Q29. Has a family member and/or significant other been supportive of an } \\
\text { interest influence in studying abroad? }\end{array}$ & $11.11 \%$ & & $33.33 \%$ & $27.78 \%$ & $27.78 \%$ \\
\hline $\begin{array}{l}\text { Q30. Do work and/or co-op commitments influence your decision to study } \\
\text { abroad? }\end{array}$ & & $13.89 \%$ & $30.56 \%$ & $36.11 \%$ & $19.44 \%$ \\
\hline $\begin{array}{l}\text { Q31. Does the Music Industry Program's curriculum content impact your } \\
\text { decision to study abroad? }\end{array}$ & $11.11 \%$ & $11.11 \%$ & $36.11 \%$ & $13.89 \%$ & $27.78 \%$ \\
\hline Q32. Is it important to find work or a co-op while studying abroad? & $11.11 \%$ & $16.67 \%$ & $33.33 \%$ & $27.78 \%$ & $11.11 \%$ \\
\hline $\begin{array}{l}\text { Q33. Is it important to have real life experiences that connect with what } \\
\text { you have learned in the Music Industry Program? }\end{array}$ & & & $5.56 \%$ & $38.89 \%$ & $55.56 \%$ \\
\hline
\end{tabular}

Table 3. Factors influencing study abroad participation. 


\section{Global Awareness}

The initial set of questions focused on the Music Industry Program students' views in relation to global awareness. Those who had not studied abroad answered questions which focused mainly on an assessment of global awareness, curriculum, and reasons for not studying abroad, while those who had studied abroad answered questions which examined global awareness, curriculum, studying abroad, and outcomes from being abroad.

Curricular Content - According to both sets of interview subjects, the composition of the Music Industry Program does not appear to significantly contribute to student global awareness. When asked, What is your opinion of the amount of information in terms of music and industry outside the United States?, there was near universal response from students that if there was information provided in courses that touched on the industry outside of the United States, it was far too minimal, with responses ranging from "I feel like it's pretty limited" to "I don't think there's enough" content offered. A few respondents also mentioned that either the information strictly focused on the United States or was not especially revelatory regarding markets outside of the domestic market with a junior female student commenting, "we're kind of lacking in sort of like an in-depth or just a general knowledge of the music industry in different countries."

The only significant difference noted between the two sets of subjects was that those who had been abroad spoke in vivid detail about the benefits of studying in another country, whether imbibing educational or cultural insights through classes or personal interactions that enhanced their awareness in both broad and specific ways, clearly illustrating that curricular content can help to not only form data rich memories, but also bolster and retain information. Overall, the interviews reinforced the survey data which showed how little connections are being made between existing curriculum, the global industry and, potentially, the reason to study abroad.

Global Awareness - Interview subjects included both those who had studied in short-term intensives and termlength study abroad programs. As with the survey respondents, both sets of interview subjects felt they were sufficiently globally aware. However, those who had not studied abroad readily acknowledged that studying abroad would have broadened their global awareness. As a male who had not studied abroad stated when asked, Do you feel that study abroad would have impacted your level of global awareness?

I definitely think so. I think a lot of people believe they have a good global perspective, you know, like reading the news or interacting with global com- munities online, but it never is a substitute for, you know, really traveling to a place and interacting with those people you know person to person.

Students who had studied abroad, whether having participated in a short-term intensive or term-length exchange, believed their global awareness had been positively increased by the experience and that it had provided supplemental and/ or entirely new material on the international music industry. As one female graduate stated, "being abroad for a little bit definitely helped me understand the South American markets that I wouldn't have had otherwise." The study abroad contingent also mentioned the importance of understanding that not only the world, but that an industry, exists outside of the United States, and that a possibility to operate in that arena is full of potential and that communication within the field is a critical component to understanding others unlike themselves.

\section{Cultural Competency}

The next set of interview questions were used to measure cultural competency and probed proficiency among and with others unlike themselves. The focus of the questions for those who had not studied abroad revolved around whether their Drexel experience had caused an increase in communication with, and understanding of, those from other cultures while also addressing student desire and ability to work in the global environment. For those who did study abroad, the questions concentrated on whether the students felt the study abroad experience had caused any change in their cultural competency, understanding of the global music industry, and interest in becoming a part of the global music industry workforce.

Cultural Competency - The interviews provided much the same results regarding general cultural competency as the survey, as both cohorts responded to the questions situated within acceptable boundaries. Neither those who had or had not studied abroad believed they had any significant existing issue with cultural communication, intercultural sensitivity and thus, their overall cultural competency. In addition, the fact that Drexel is a culturally diverse university located in an urban center was mentioned by more than one individual as facilitating the expansion of individual cultural competency by sheer nature of exposing students to multicultural individuals and attitudes during their daily routine and it is worth noting that this may also account for the consistency between the interview and survey results on this topic. While all four students who studied abroad did state that they believe their cultural competence improved post-study abroad, none of these students expressed any indication that it had suffered prior-only that it had increased after participating in a study abroad program. Clearly, even without existing deficiencies in cultural competency, it is 
evident that study abroad has the possibility to offer students an opportunity to continue to expand upon their existing level of competency.

Career Development - A more significant finding related to cultural competency was in relationship to career development. Both sets of respondents were asked a series of questions related to working outside of the United States that included, among other questions specific to each cohort, Have you considered the possibility that the "dream" job you described to me earlier may entail dealing with individuals from another country? How do you feel about this?, and How comfortable would you feel if you were asked to be involved in the marketing of a music product in a country other than the United States?

Individuals who had not studied abroad but whom had already dealt with people or industry outside of the United States during co-op or in the course of their career, responded that while not opposed to working outside of the United States, or with others outside of the United States, they might require, "like a crash course. You know, just a little update or something" or "would need to ask a lot of questions" to ensure some level of success. While any intelligent marketer would survey the market in order to properly do one's job, these responses suggest an uneasiness with the global market, especially in glaring comparison to the cohort who studied abroad. The group who studied abroad expressed their willingness in less intangible terminology and with greater enthusiasm and overall positivity at the prospect of marketing a product or working in an out-of-country environment without hesitation. This is best exemplified by a female junior who stated,

I definitely feel prepared to work in a global environment and...I really want to work in a global music environment. I really want to be able to travel all around and - not even travel all around - but be in one place that I'm not used to and work.

As Clarke III et al. found, "Students who study abroad are more likely to have higher levels of intercultural proficiency than students who do not study abroad" (2009) and in this regard, the interview results from those who studied abroad demonstrate a higher aptitude for the global industry and an ability to move seamlessly within it.

\section{Factors Influencing Students' Decision to Study Abroad}

Ultimately, it is critical to understand why some individuals chose to study abroad while others did not. To answer this, those who had not studied abroad were asked, Can you explain why you did not study abroad? The cohort cited two primary reasons for not participating in studying abroad: financial and curriculum-related issues.
Financial - Given the results of the survey in which a combined total of $75 \%$ of students responded that cost was an influence on their decision to study abroad, it is not surprising that financial considerations were mentioned in three of the four interviews as the main reason for not studying abroad. While program cost itself was an issue, it was not the only financial anxiety mentioned by students. Numerous variations were cited that included basic financial stability, i.e., paying for college versus the value of study abroad, and concerns about having to leave work commitments at home and finding work in another country in order to support themselves. This is consistent with the findings of Doyle et al. who found that, "The cost of studying overseas was identified as the most important obstacle by students asked to select from a series of potential obstacles" (2010) and which was echoed in an interview with a senior male who expressed the multiple financial pressures that weighed on his decision:

The time that I spent there [studying abroad] I would probably need to get another job to pay for some of my other expenses and what am I going to do? Go to another country to work a part-time job there, at a lesser rate?

With anxiety towards financial status, undertaking study abroad becomes an untenable option for some students, especially given the lack of curricular material in the global music industry to support an interest in study abroad.

Specialized Curriculum - Curriculum design figured into decision-making because either the programs respondents may have been interested in did not specifically address music industry content or help fulfill specific requirements for graduation. In addition, the Music Industry Program major is highly specialized and students expressed difficulty in finding comparable course offerings or matches in study abroad programs. Stroud found that majors with more intensely structured sequences "suggest that unsupportive faculty member or inflexible requirements within the major impede certain majors from even considering study abroad" (2010). This thinking, whether real or perceived, was verbalized by the subjects who did not study abroad because they feared it may delay their graduation. This is because course requirements and schedules within the Music Industry Program curriculum are rigidly organized so that students who miss a term or class may be at a disadvantage, as some courses may only be offered once a year.

It is not enough to understand why individuals choose not to go abroad. It is also important to understand why individuals make the choice to study abroad. Thus, the group of individuals who had studied abroad were asked, What made you interested in studying abroad?, and the respondents' 
answers fell into one or both of two dominant and related themes: enthusiasm for travel and/or time commitment.

Travel Enthusiasm - Two interview participants had grown up traveling extensively and had both participated in two or more study abroad programs. Other students mentioned the opportunity, or continued opportunity, to travel outside of the country as one of the most attractive aspects of study abroad. This correlates with the survey data where prior exposure to travel outside of the United States appears to pave the way for interest in study abroad.

Value and Time Commitment - Students talked about wanting to study abroad because existing study abroad options did one of the following: the program either fit into existing Music Industry Program curriculum or it did not complicate graduation in addition to offering specific music industry content or fulfilling other required course credits while offering exposure to another culture. This is consistent with the findings of Salyers et al. that, "Students discussed the value of gaining course credits while also having the opportunity to travel as a strong motivator" (2015) for study abroad in addition to reinforcing the survey results that showed that curriculum does have a role to play in student decisions. According to interview respondents, the material contained in study abroad classes also appears to contribute heavily to student involvement when it is clear that material and information will increase the knowledge base of an individual without compromising one's path to completing a degree program. As one female graduate opined, "I wanted something that would fit with the program...Brazil was the only one that really allowed me to get all of my classes that I needed while still getting to go abroad," because it revolved around music and fulfilled an elective requirement. These responses illustrate the importance of building content-rich and program-specific opportunities that work with students' intensive time demands, particularly within specialized curricula such as the Music Industry Program.

The results of this research have produced unanticipated results with Drexel Music Industry Program students establishing themselves as broadly more globally aware and culturally competent than anticipated. This could be attributed to the vast number of survey and interview respondents who have traveled and interacted with individuals outside of the United States and who have an interest in study abroad. In both the areas of global awareness and cultural competency, as supported in prior studies, study abroad proved to increase the levels of both, even if neither area was lackingthough the obvious exception is the content-specific area of the global music industry, where those who studied abroad gained immeasurable value in these areas.

The research also illustrated that curriculum content and structure, for both program and study abroad offerings, can be persuasive on increasing cultural competence and influ- encing choice. Without existing global connection in course content, students may find it difficult to understand the benefits of studying abroad. If curricular structure impedes the ability to go abroad, or study abroad options do not include courses that fulfill requirements, students will not take advantage of the opportunities. This study also reinforced previous research on how student financial situation impacts choice and how the decision to study abroad may be constrained by work commitment and loss of income.

\section{Conclusion}

This study resulted in three major conclusions. First, Drexel's Music Industry Program curriculum should make a stronger connection with the global music industry in order to help initiate interest in the music community outside of the United States. The results indicated that the curriculum is not effectively incorporating information on the global music industry into its courses. If the curriculum included more content on the global industry that focuses on the business environment, musical climate, and cultural impact of several countries, it could perhaps encourage students to feel more comfortable in the global environment and consider studying abroad due to an increased knowledge of the worldwide industry.

Second, whenever possible, study abroad programs should be implemented or refined in order to be less of an obstacle to completing graduation requirements and work well with the Music Industry Program curriculum while also containing relevant music industry courses and content. Also, partnering with other institutions that specialize in music industry as well as offering more flexible options of study (i.e., spring break intensive, fall break-in, etc.) could help build more attractive opportunities for Music Industry Program students and illustrate the program's commitment to global learning.

Third, value and legitimacy must be given to the industry and career opportunities outside of the United States so that students understand study abroad as a potential tool for future professional gain rather than financial drain. Implementation in the curriculum of core course content combined with more information regarding existing study abroad opportunities and the value that students who have studied abroad have received would likely help to increase enrollment. Hearing the merit of studying abroad from peers may perhaps legitimize study abroad and lead to increased participation.

This study revealed that a desire to study abroad does exist within the Drexel Music Industry Program and has come to conclusions on how to increase the number of students who study abroad through understanding the factors that influence participation. It is hoped that this research will be utilized to inform both Drexel's Music Industry Program 
and the studies of music industry and study abroad. Music is beloved around the world and it is critical to help understand how to help motivate students of music industry to see and appreciate the global music market.

\section{Appendix A. Survey Overview and Informed Consent Form for the Study of Factors Influencing Study Abroad Participation}

Hello,

I am Darren Walters, an Associate Teaching Professor and graduate student in Drexel University's Global and International Education Program. As part of my research thesis, I am conducting a survey on Music Industry Program student's attitudes on global awareness and the factors that influence participation in study abroad. Should you participate in his survey, you will be providing valuable information to my research.

This survey is entirely anonymous and utilizes Survey Monkey to tabulate results. By participating in the survey, you understand that no identifying information may be used; however, the demographic information collected in the survey may be utilized in the research for descriptive purposes only. All data will be shared with my supervising professor and may be used in future publication and in presentations, but responses will remain anonymous.

Your consent is hereby freely given to the terms of the survey participation. However, you may choose to withdraw from the survey at any time without any repercussions. Should you have questions or concerns, please email me atdmw62@drexel.edu

To proceed to the survey, please visit the link below: Surveymonkey.com

After completing the survey, visit Surveymonkey.com to enter to win a \$25 gift card as thank you for your participation. 


\section{Appendix B. Student Survey for the Study of Factors Influencing Study Abroad Participation}

\section{Demographics}

1. How do you identify your gender?
a. Male
b. Female
c. Non-binary
d. Other

2. How do you identify your race?
a. White
b. Black or African-American
c. Hispanic or Latino
d. Native American or American Indian
e. Asian or Pacific Islander
f. Other

3. What is your age?
a. Under 18
b. 18
c. 19
d. 20
e. 21
f. 22
g. 23
h. 24

If under 18 , please do not continue this survey.

4. What is your current academic classification?
a. Freshman
b. Sophomore
c. Junior
d. Senior

5. What is your Music Industry Program concentration?
a. Business
b. Recording Arts and Music Production (RAMP) aka "Tech"

6. How far do you live from your permanent home while attending Drexel University?
a. I live at home
b. I live within 25 miles
c. I live within $25-50$ miles
d. I live within 50-100 miles
e. I live 100 or more miles away

7. What is the highest level of education you hope to attain?
a. Bachelors
b. Graduate
c. Doctorate or Professional degree

\section{Global Awareness}

8. Have you ever visited a foreign country?
a. Yes
b. No

9. Have you ever taken a course at Drexel University that involved the study of a foreign culture?
a. No
b. Yes

10. Drexel University's Music Industry Program classes have helped me to draw connections with the global music industry.
a. Not at all
b. Small degree
c. Moderate degree
d. High degree
e. Very high degree

11. I believe that the world and its cultures are all connected.
a. Not at all
b. Small degree
c. Moderate degree
d. High degree
e. Very high degree

12. I have listened to non-English language music.
a. No
b. Yes

13. I have watched or read a non-U.S. news source.
a. No
b. Yes

14. I become informed on controversial international issues prior to developing a point of view.
a. Not at all
b. Small degree
c. Moderate degree
d. High degree
e. Very high degree

15. I consider current issues that affect individuals living in developing countries.
a. Not at all
b. Small degree
c. Moderate degree
d. High degree
e. Very high degree 
16. I am informed of issues that affect global security, economics, human rights and the environment.
a. Not at all
b. Small degree
c. Moderate degree
d. High degree
e. Very high degree

17. Equality and justice are human values that should extend to all groups of individuals regardless of race, religion or lifestyle.
a. Not at all
b. Small degree
c. Moderate degree
d. High degree
e. Very high degree

\section{Cultural Competency}

18. I seek out diverse individuals and situations.
a. Not at all
b. Small degree
c. Moderate degree
d. High degree
e. Very high degree

19. I am comfortable around individuals from other cultures.
a. Not at all
b. Small degree
c. Moderate degree
d. High degree
e. Very high degree

20. Part of a college education should include exposure to individuals, cultures, races, ideas and sexualities that are different than my own.
a. Strongly disagree
b. Disagree
c. Neither agree nor disagree
d. Agree
e. Strongly agree

21. I respect the right of individuals to participate in cultures, religions and family structures different from my own.
a. Strongly disagree
b. Disagree
c. Neither agree nor disagree
d. Agree
e. Strongly agree

22. I am open-minded and resist stereotypes about those unlike myself.
a. Not at all
b. Small degree
c. Moderate degree
d. High degree
e. Very high degree

23. My beliefs and value systems are more important than others.
a. Strongly disagree
b. Disagree
c. Neither agree nor disagree
d. Agree
e. Strongly agree

\section{Study Abroad}

24. Are you interested in studying abroad?
a. Not at all
b. Small degree
c. Moderate degree
d. High degree
e. Very high degree

25. Are you aware of the current Music Industry Program study abroad options to Brazil and Australia?
a. Not at all
b. To a little extent
c. To some extent
d. To a great extent
e. To a very great extent

26. Does program cost influence your decision to study abroad?
a. Not at all
b. To a little extent
c. To some extent
d. To a great extent
e. To a very great extent

27. Is study abroad location important to you?
a. Not at all
b. To a little extent
c. To some extent
d. To a great extent
e. To a very great extent 
28. Is study abroad in a non-English language location study abroad important, even if instruction will be in English?
a. Not at all
b. To a little extent
c. To some extent
d. To a great extent
e. To a very great extent

29. Has a family member and/or significant other been supportive of an interest influence in studying abroad?
a. Not at all
b. To a little extent
c. To some extent
d. To a great extent
e. To a very great extent

30. Do work and/or co-op commitments influence your decision to study abroad?
a. Not at all
b. To a little extent
c. To some extent
d. To a great extent
e. To a very great extent

31. Does the Music Industry Program's curriculum content impact your decision to study abroad?
a. Not at all
b. To a little extent
c. To some extent
d. To a great extent
e. To a very great extent

32. Is it important to find work or a co-op while studying abroad?
a. Not at all
b. To a little extent
c. To some extent
d. To a great extent
e. To a very great extent

33. Is it important to have real life experiences that connect with what you have learned in the Music Industry Program?
a. Not at all
b. To a little extent
c. To some extent
d. To a great extent
e. To a very great

Appendix C. Student Interview Overview and Informed Consent Form for the Study of Factors Influencing Study Abroad Participation

Hello,

I am Darren Walters, an Associate Teaching Professor and graduate student in Drexel University's Global and International Education Program. As part of my research thesis, I am conducting student interviews on Music Industry Program students' views in relation to global awareness and cultural competency. Should you participate in this interview, you will be providing valuable information. In order to do the research, I need students who have studied abroad and those who have not, which is why I have contacted you.

This interview is entirely anonymous and you understand that no identifying information may be used; however, the information collected may be utilized in the research. All data will be shared with my supervising professor and may be used in future publication and in presentations, but the interview will remain anonymous.

Your consent is given to reproduce these interviews utilizing a pseudonym in order to disseminate the outcomes of this study if needed. This interview will be confidential and held off site in a safe environment where only the interviewer will have access.

Your consent is hereby freely given to the terms of the interview participation. However, you may choose to withdraw from the interview at any time without any repercussions. Should you have question or concerns, please email me atdmw62@drexel.edu

By signing below, I am freely consenting to participate in an interview with Darren Walters for the purpose of a research thesis on factors influencing study abroad participation within the Global and International Education Program at Drexel University. I understand that this interview is given at will and that I am able to cease at any time without any repercussions.

Name:

Date

Concentration:

Current academic classification:

Location:

Time 


\section{Appendix D. Student Interview Questions for the Study of Factors Influencing Study Abroad Participation: Study Abroad Student Interviews}

Thank you for taking time out of your schedule to meet with me today. I really appreciate it because this interview will help me to understand how study abroad may have affected your views in relation to global awareness and cultural competency. First, I would like to get to know more about you personally that perhaps I may not already know. Is that okay with you? Great!

\section{Background Information}

1. What made you want to study the music industry?

2. Tell me about the 'dream' job you hope to secure in the music industry when you graduate.

\section{Global Awareness}

3. What is your opinion of the amount of information the Music Industry Program curriculum provides in terms of music and industry outside the Unites States?

4. Please describe the type of study abroad program in which you participated. Where and when did you study abroad?

5. What made you interested in studying abroad?

6. Had you had any previous exposure to, or experience with, the country you traveled to in any of your Drexel classes?

7. What was your favorite part of study abroad? Any particular activity, event, interaction or field trip?

8. What is the most important thing you learned?

9. Do you recall any particular item of interest about music or the music industry outside of the United States that you learned?

10. In what ways did your study abroad experience ignite an interest in the culture you visited or any other culture?

11. Can you explain how study abroad may have impacted your level of global awareness?

\section{Cultural Competency}

12. After participating in study abroad, can you explain if you experienced any change in your cultural competency skills?

13. After participating in study abroad, can you explain if you experienced any change in your intercultural communication skills?
14. After participating in study abroad, can you explain if you experienced any change in your cultural sensitivity?

15. After participating in study abroad, did you experience any shift in your perception of the global music industry?

16. Did study abroad prepare you to work in a global environment?

17. Prior to studying abroad had you considered working in another country? What about now?

18. Have you considered the possibility that the 'dream' job you described to me earlier may entail dealing with individuals from another country? How do you feel about this?

19. How comfortable would you feel if you were asked to be involved in the marketing of a music product in a country other than the United States?

20. Did you establish any professional contacts while studying abroad with who you remain in contact?

21. After returning from studying abroad, did you experience any change in your academic or career goals? If so, is there a specific incident that you would relate this to?

22. Have you experienced any unintended outcomes as a result of study abroad?

Thank you for your time, I really appreciate it. You have been very helpful. 


\section{Appendix E. Student Interview Questions for the Study of Factors Influencing Study Abroad Participation: Non-Study Abroad Student Interviews}

Thank you for taking time out of your schedule to meet with me today. I really appreciate it because this interview will help me to understand how your decision not to study abroad may have affected your views in relation to global awareness and cultural competency. First, I would like to get to know more about you personally that perhaps I may not already know. Is that okay with you? Great!

\section{Background Information}

1. What made you want to study the music industry?

2. Tell me about the 'dream' job you hope to secure in the music industry when you graduate.

\section{Global Awareness}

3. What is your opinion of the amount of information the Music Industry Program curriculum provides in terms of music and industry outside the Unites States?

4. Do you recall any particular item of interest about music or the music industry outside of the United States that you learned?

5. Can you explain why you did not study abroad?

6. Though you did not study abroad, have you had another significant cultural experience that you could share?

7. Do you feel that study abroad would have impacted your level of global awareness?

\section{Cultural Competency}

8. While at Drexel have you experienced any change in your cultural competency skills?

9. While at Drexel have you experienced any change in your intercultural communication skills?
10. While at Drexel have you experienced any change in your cultural sensitivity?

11. While at Drexel have you experienced any shift in your perception of the global music industry?

12. Do you feel prepared to work in a global environment?

13. Have you considered working in another country?

14. Have you considered the possibility that the 'dream' job you described to me earlier may entail dealing with individuals from another country? How do you feel about this?

15. How comfortable would you feel if you were asked to be involved in the marketing of a music product in a country other than the United States?

16. Have you established any professional contacts outside of the United States with whom you remain in contact?

17. While at Drexel have you experienced any change in your academic or career goals? If so, is there a specific incident that you would relate this to?

Thank you for your time, I really appreciate it. You have been very helpful. 


\section{References}

Anderson, Phillip H., Leigh Lawton, Richard J. Rexeisen, and Ann C. Hubbard. "Short-term study abroad and intercultural sensitivity: A pilot study." International Journal of Intercultural Relations 30, no. 4 (July 2006): 457-469. https://doi.org/10.1016/j.ijintrel.2005.10.004.

Braskamp, Larry A., David C. Braskamp, and Kelly Merrill. "Assessing Progress in Global Learning and Development of Students with Education Abroad Experiences." Frontiers: The Interdisciplinary Journal of Study Abroad 18 (Fall 2009): 101-118.

Cho, Jaee and Michael W. Morris. "Cultural study and problem-solving gains: Effects of study abroad, openness, and choice." Journal of Organizational Behavior 36, no. 7 (2015): 944-966. https://doi.org/10.1002/ job.2028.

Clarke III, Irvine, Theresa B. Flaherty, Newell D. Wright, and Robert M. McMillen. "Student Intercultural Proficiency From Study Abroad Programs.” Journal of Marketing Education 31, no. 2 (May 2009): 173-181. https://doi.org/10.1177/0273475309335583.

Clarke, Velta. "Students' Global Awareness and Attitudes to Internationalism in a World of Cultural Convergence." Journal of Research in International Education 3, no. 1 (April 2004): 51-70. https://doi. org/10.1177/1475240904041461.

Commission on the Abraham Lincoln Study Abroad Fellowship Program. Global Competence \& National Needs: One Million Americans Studying Abroad. Washington DC: Lincoln Commission, 2005. https:// www.aifs.com/pdf/lincoln final report.pdf.

Doyle, Stephanie, Philip Gendall, Luanna H. Meyer, Janet Hoek, Carolyn Tait, Lynanne McKenzie, and Avatar Loorparg. "An Investigation of Factors Associated With Student Participation in Study Abroad." Journal of Studies in International Education 14, no. 5 (May 2009): 471-490. https://doi. org/10.1177/1028315309336032.

Gibson, Shonda, and Stephen Reysen. "Representations of Global Citizenship in a School Environment." International Journal of Education Research 8, no. 1 (Fall 2013):116-128.

Hatschek, Keith. "Balancing Music Industry Curricula in Undergraduate Degree Programs: A Course Distribution Survey and Analysis." Journal of the Music and Entertainment Industry Educators Association 11, no. 1 (2011): 161-211. https://doi.org/10.25101/11.7.

Ipsos Connect. Music Consumer Insight Report 2016. London: IFPI, 2016. http://www.ifpi.org/downloads/ Music-Consumer-Insight-Report-2016.pdf.
Kitsantas, Anastasia. "Studying abroad: the role of college students' goals on the development of cross-cultural skills and global understanding." College Student Journal 38, no. 3 (September 2004): 441-452.

Li, Manyu, Josephine E. Olsen, and Irene Hanson Frieze. "Students' Study Abroad Plans: the Influence of Motivational and Personality Factors." Frontiers: The Interdisciplinary Journal of Study Abroad, 23 (Fall 2013): 73-89.

Lörz, Markus, Nicolai Netz, and Heiko Quast. "Why do students from underprivileged families less often intend to study abroad?" Higher Education 72, no. 2 (August 2016): 153-174. https://doi.org/10.1007/ s10734-015-9943-1.

Mohajeri Norris, Emily, and Joan Gillespie. "How Study Abroad Shapes Global Careers: Evidence From the United States." Journal of Studies in International Education 13, no. 3 (2009): 382-397. https://doi. org/10.1177/1028315308319740.

“Open Doors 2016 Executive Summary." Institute of International Education. New York: IIE, 2016. https://www.iie.org/en/Why-IIE/Announcements/2016-11-14-Open-Doors-Executive-Summary.

Salisbury, Mark H, Paul D. Umbach, Michael B. Paulsen, and Ernest T. Pascarella. "Going Global: Understanding the Choice Process of the Intent to Study Abroad." Research in Higher Education 50, no. 2 (March, 2009): 119-143. https://doi.org/10.1007/s11162-0089111-x.

Salyers, Vince, Cathy S. Carston, Yasmin Dean, and Chad London. "Exploring the Motivations, Expectations, and Experiences of Students Who Study in Global Settings." Journal of International Students 5, no. 4 (2015): 368-382. Retrieved from http://www.library. Drexel.edu/cgi-bin/r.cgi/login?url=http://search.proquest.com/docview/1695740264? accountid=10559.

Smith, Patricia Joanne, and Lawrence J. Mrozek. "Evaluating the Application of Program Outcomes to Study Experiences." Honors in Practice 12 (2016): 9-32. Retrieved from http://digitalcommons.unl.edu/nchchip/249/.

Stroud, April H. "Who Plans (Not) to Study Abroad? An Examination of U.S. Student Intent." Journal of Studies in International Education 14, no. 5 (2010): 491-507. https://doi.org/10.1177/1028315309357942.

“Trends in U.S. Study Abroad.” NAFSA: Association of International Educators. n.d. http://www.nafsa.org/Policy and Advocacy/Policy_Resources/Policy Trends and Data/Trends in U S Study_Abroad/. 
Wang, Jia, Ali Peyvandi, and Betty S. Coffey. "Does a Study Abroad Class Make a Difference in Student's Global Awareness? An Empirical Study." International Journal of Education Research 9, no. 1 (Spring 2014): 151-162. Retrieved from http://go.galegroup.com/ps/i.do?p=A$\underline{\text { ONE\&sw }=\text { w\&u }=\text { Drexel_main } \& v=2.1 \& i t=r \& i d=-}$ $\underline{\text { GALE } \% 7 C A 381408710 \& \text { sid }=\text { summon\&asid }=816 \text { de- }}$ 2a2bd126f5af2fbc70134024217.

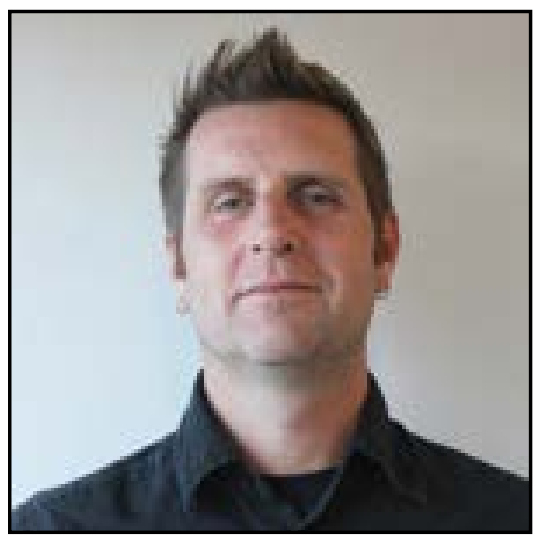

Darren Walters has thirty years of music industry experience that spans the entrepreneurial and academic and has allowed him to experience the nuances of the industry from a variety of perspectives. As an Associate Teaching Professor at Drexel University, Darren is responsible for teaching core music business classes and is the Director of the MAD Dragon Music Group, which comprises the MAD Dragon Records enterprise, a key component of experiential learning for Drexel music business students. In addition, Darren designed the Music Industry Program's first study abroad course, an in-depth focus on the music and culture of Brazil. Until its sale to Epitaph Records in 2017, Darren was co-owner of the independent record label Jade Tree, which he co-founded in 1990 where he was the Label Manager, providing company leadership, strategic financial and business direction, $A \& R$, and project marketing. 


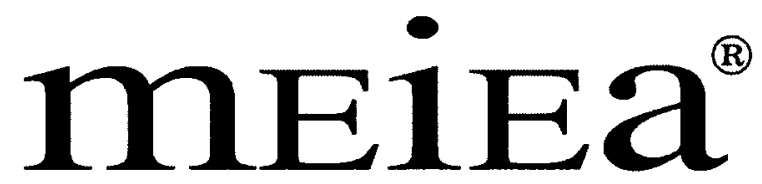

MUSIC \& ENTERTAINMENT INDUSTRY

EDUCATORS ASSOCIATION

\section{PROCEEDINGS OF THE \\ 2018 INTERNATIONAL SUMMIT}

OF THE

\section{MUSIC \& ENTERTAINMENT INDUSTRY EDUCATORS \\ ASSOCIATION}
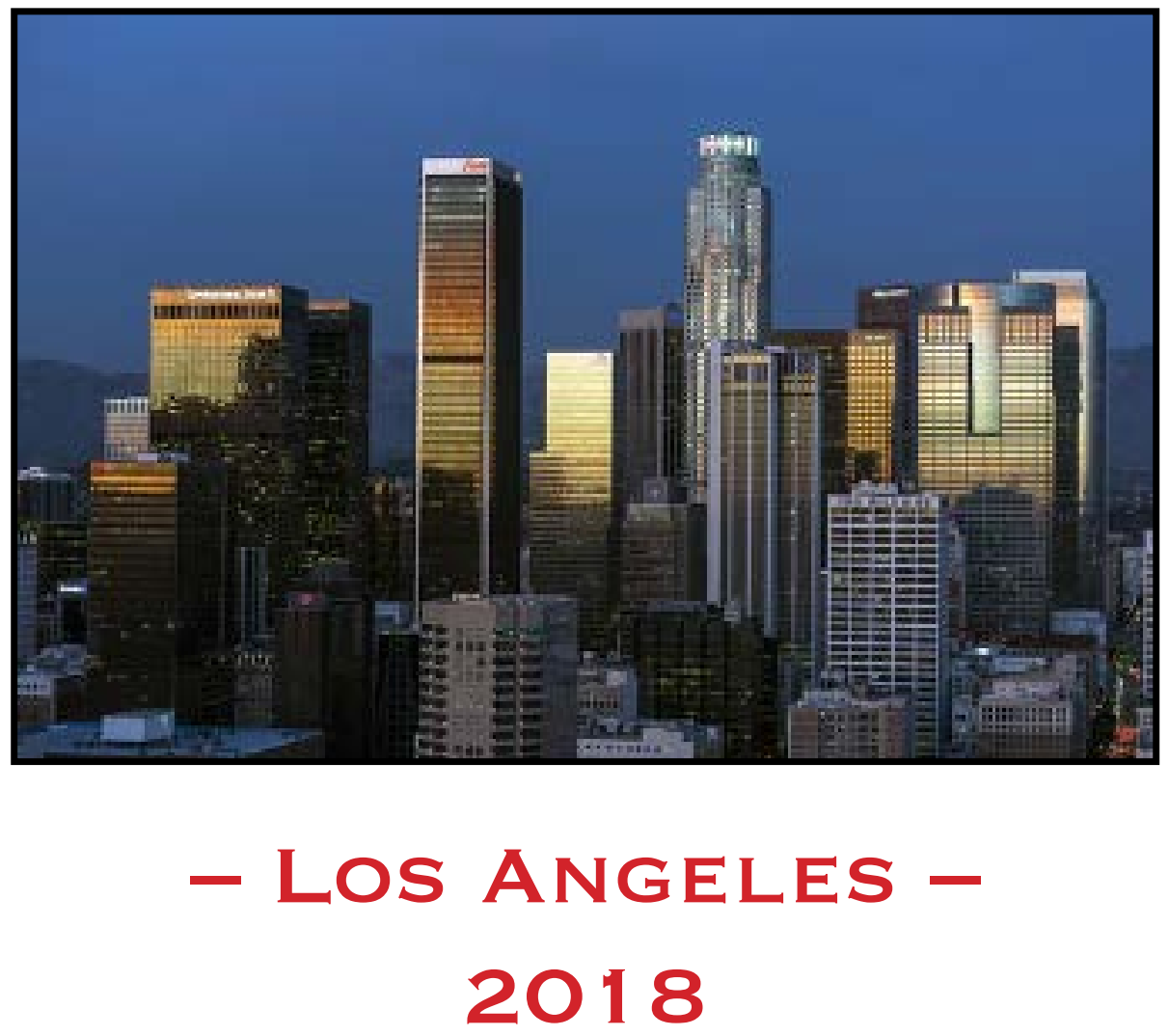

March 22 - 24, $2018 \cdot$ Embassy Suites by Hilton - Los Angeles/Glendale 